\title{
The Boundaries of Scientific Innovation in the EU Green Deal Context
}

\author{
Aija RUSE ${ }^{1 *}$, Jelena PUBULE ${ }^{2}$ \\ ${ }^{1}$ Institute of Energy Systems and Environment, Riga Technical University, Azenes iela 12/1, Riga, Latvia \\ ${ }^{1,2}$ Center of High Energy Physics and Accelerator Technologies, Riga Technical University, \\ Azenes iela 12/1, Riga, Latvia
}

\begin{abstract}
The dynamics of global energy and climate agenda progresses rapidly. The European Union has frequently taken an active role in international climate policy by developing relevant strategies in as early as the nineties the last century, and today promoting an ambitious EU Green Deal to become climate neutral by 2050 . However, despite its ambition and recent success in meeting most 2020 goals, the $\mathrm{EU}$ does not have an easy schedule to progress on its climate and energy targets for 2030 . Recognizing the transition, one of the scientific excellences European Organisation for Nuclear Research (CERN) published the first environmental report in the beginning of 2020. Through a wide range of environmental activities and clearly disseminated targets, this organisation actually brought to the table a discourse on how scientific organisation can be part of $E U$ Green Deal actions and how to perform research within the scope of the environmental context. This article focuses on two concepts to contribute to larger discussions in both the research and governance communities, how researchers should conduct their science, and what respective responsibilities of researchers, their institutes, have in terms of European environmental policy. Literature was reviewed to find a theoretical approach to the environment, responsible innovation and science diplomacy. The research was developed through literature study to identify and describe the respective indicators as well as through an analysis of secondary sources whereby a previous attempt to collect and analyse other sources had been conducted by scholars in respect to the relationship between innovation and the environment.
\end{abstract}

Keywords - Environmental policy; European Organisation for Nuclear Research; responsible innovation; science diplomacy

\section{INTRODUCTION}

The dynamics of global energy and climate agenda is advancing very rapidly [1], the European Union has always taken an active role in international climate policy by developing relevant strategies in as early as the nineties of the last century, and currently promoting an ambitious EU Green Deal to become climate neutral by 2050 . However, in spite of its ambition and recent success in meeting most of its 2020 goals, the EU is not on an easy schedule to progress on its climate and energy targets for 2030 [2]. Whereas we can look at innovative and responsible science not only as an instrument for developing green technologies, but also as a powerful social tool in use of technologies and ideological driving force behind the values towards driving environmentally sound policies [2]. The diverse

\footnotetext{
* Corresponding author.

E-mail address: aija.ruse@rtu.lv
} 
angles to look at the science can actually be considered as one of the important tools to trigger change.

While there are many other environmental activities before, the CERN first environmental report published recently summarising particular environmental targets settled by the organisation can be considered as the powerful indicator of transition processes in one of the scientific excellences European Organisation for Nuclear Research (CERN). The prioritisation of environmental activities and a clear dissemination of targets in this high energy physics community gives us a framework for discussion on how scientific organisations can be part of Green Deal values and whether it is possible to perform intricate global scale research within the scope of the environmental context given suggested by EU policy.

This article focuses on the intersections of the two concepts in order to contribute to broader discussions in both research and governance communities, to establish how researchers should conduct their science, and what respective responsibilities researchers and their institutes have towards the European Green Deal policy and climate change.

The article is structured as follows. First, we summarise the research methods and techniques used to analyse the data assembled in this research. Secondly, we outline the logic for doing this research on responsible innovation and science diplomacy in the context of sustainability and environmental policy and in particular in relation to the EU Green Deal ideas. Then, the case analysis about the European Organisation for Nuclear Research in the light of its diverse environment programme is presented. Finally, we describe key findings within the framework of the present research, as well as opportunities for further analyses on the subject.

\section{Methodology}

A literature review is conducted in order to establish an idea of the current status of the research on the subject [3]. The main idea is to lay out the patterns where researchers within the field have provided a stimulus to established ideas, policies and their implementation towards the ideas of EU Green deal.

This study assembles the following types of information sources:

- Research literature;

- EU policy documents;

- Digital media publishing.

The analyses of the above sources were developed to identify and contextualise the interrelations between responsible and innovative science and the environment [4].

In this research paper, the literature analysis was developed to identify and describe the indicators of innovation with the idea to describe the distinctive nature of the relationship (or the lack thereof) between innovation and the environment.

The literature review in this research paper on the nature of the relationship [5] between science and the environment was flagged by two key questions:

1. What do research findings tell on the subject on the relationship between innovative and responsible science and the EU Green Deal?

2. What do research findings tell on the subject on the relationship between science diplomacy and EU environmental policy?

The process of systematic literature review process was comprised of the following:

- Definition of criteria for study papers to be included in the review;

- Search of scientific databases, media articles and EU policy documents for connections 
in line with the criteria for inclusion;

- Familiarisation with relevant studies and taking notes on the details for each study;

- Recognition of common themes in the various studies;

- Analysis of common patterns contributing into answers of the above research questions [6].

To find research studies relevant to the above questions, a literature analysis was performed via a search of databases. The research sources used were the SCOPUS, Web of Science and the Willey Online Library database host. In the above-mentioned databases searches were made for the key terms from the first research question and then from the second research question: 'innovative science', and 'Green Deal', followed by 'science diplomacy' and 'EU environmental policy'. Considering the number of publications, only the period between 2015 and 2020 is reviewed and established as relevant to the analysis, especially for the first question since the targets of the Green Deal were announced by the EU in late 2019, to identify whether there is any correlation between present-day science and the current environmental targets. When all relevant studies were collected from the databases, abstracts were read carefully and searched thoroughly for clues to meet the criteria of the literature review. We included any articles that fulfilled all the criteria for the literature review. Theoretical review on interconnection between the 'innovative science' and 'EU Green Deal' demonstrates a relatively negligible number whereas the combination of 'science diplomacy' and 'EU environmental policy' seems much more common in scientific discourse.

As regards European environment policy, in recent years these concerns are integrated into other EU policy areas. However, for this paper only basic framework of EU Environmental policy documents were identified and analysed. Background information regarding European Organisation for Nuclear Research, Environmental report and Annual reports were identified at relevant scientific literature and in CERN webpage.

\section{Environmental Policy in the European Union}

The global energy and climate agenda is shaping fast, the European Union has been consistent in taking a leader role in international climate policy [1] by pursuing environment policies first in 1972, at which the Heads of State or Government acknowledge the need for a joint Community environment policy on the edge of the economic expansion, then the Treaty of Maastricht (1993) establishing the environment as an official EU policy area and introduction of 'polluter pays' principle. To help drive the change action programme, to meeting ambitious Paris Agreement goals and 2030 targets were set, and now going further and faster forcing the challenging European Green Deal to attain climate neutrality, resourceefficiency and competitive economy by 2050 [7].

The EU Green deal advocates to look at the world using a wider lens [8]. Instead of an undefined discussion of a 'green revolution' or 'selective technology hype, it focussed on the need to change systems and offered pathways of sustainability transition in order to address the key arenas damaging our environment' [8]. The European Commission announced the European Green Deal as the most ambitious and challenging goal set. With the goal to transform the European Union, 'the world's second-largest economy, to go climate-neutral by 2050.' The European Green Deal is a policy portfolio capable of fundamental changes to EU people and industries. This great European movement will transform the EU's economy for a sustainable future mastering wide range policy implementation across different fields: energy, industry, agriculture, mobility, environment, financing. The EU Green Deal sets ambitious targets, in fact, the Green Deal is centred on transforming the major consumption- 
production systems in the economy - energy, transport, construction and food [8], [9]. To reach targets, actions are set including environmentally friendly technologies, innovative industry, cleaner transport, green energy sector, energy efficient buildings which require great efforts by all sectors and in particularly scientific organisations, universities and institutes.

Studying various policies shows that major EU policy objectives the likes of the Green Deal aiming to initiate fundamental transformations, also provide a wide range of opportunities to various actors, groups of interests, economic players and businesses [10]. European policy refers to science being a crucial player concerning the development of a new, high-level health, safety, environmental protection and consumer protection since the nineties of the last century. Science, knowledge and evidence offer solutions which provide clear direction towards more resilient economies, societies and governance systems, and design environmentally sound economic strategies for the EU, increasing Europe's competitiveness and digitalisation. Thus, we can argue that to kick-start the environmental, social and economic transformations introduced by the EU Green Deal, research and innovation are two key arenas with which to build cooperation. Scientific evidence from many different areas is considered as a promising avenue to achieve the bold targets currently set. The European Commission's Communication paper for the Green Deal policy underlines direct engagement of scientific expertise in various fields - biodiversity, toxic-free environment, management of environmental disasters, moreover much research underlines the necessity to implement the Green Deal environmental measures within current scientific activities. When speaking about the major policies which are transformative in society on a broad scale in the world, there is a large variety of driving forces for transformation, including visionaries, changing values, charismatic political leaders, stakeholder engagement, dissemination, regulations, innovations, international trade agreements, progressive technological change, expression of new ideas through arts, entertainment, and literature, changes in everyday habits, and financial instruments encouraging green technologies, circular economy initiatives fundamentally changing today's economic order. The economic measures encompass a broad range of actions from green finance initiatives and circular-economy incentives to replacing the current political-economic in order to achieve sustainability [9].

There are several ways how EU environmental policy looks at the stakeholders in science - as a role player promoting sustainable future values and also as a technology innovator. For example, universities are perfectly positioned to involve students and their families as well as society as a whole to accomplish the needed changes for sustainable transformation. Also, scientific expertise is indispensable in coming up with concrete solutions on how to safeguard society and to protect the environment against pollution. In order to support stakeholders in science, the EU invests financing through EU programmes such as Horizon Europe and others.

However, the analysis of data shows that science is mostly viewed as an instrument for developing green technologies, and less as an ideological driving force behind the values towards driving environmentally sound policies [2]. Moreover, the EU has considered science as a great player in this ambitious movement able to provide not only concrete technological solutions but also behaviour standards towards a sustainable future.

\section{RESPONSIBLE AND INNOVATIVE SCIENCE}

Although research and innovation are crucially important to reach targets set in EU policy, scientists on a global scale have generally be independent from political and governmental agenda, therefore providing a safe environment free of political accountability [11]. This freedom could be used by scientific organisations to make efforts in innovation 
promoting the indisputable link between society, environment and technology unencumbered by a political or misguided financial agenda. Moreover, science and technology by their scale besides the obvious technical impact has responsibility in the social and political arenas [11]

Winner, suggests the following definition of responsible research and innovation: 'A transparent, interactive process by which societal actors and innovators become mutually responsive to each other with a view to the (ethical) acceptability, sustainability and societal desirability of the innovation process and its marketable products (in order to allow a proper embedding of scientific and technological advances in our society).' [12] The inception of responsible innovation is founded not only on academic concept, but also considering normative impact and therefore strives to achieve that 'science and innovation are directed at, and undertaken towards, socially desirable and socially acceptable ends, with connotations of trust and integrity' [13]. While science has always had to be responsible in its execution and products, in the frame of the legal context the notion of responsible innovation has developed over the last ten years [13]. In various ways, this reshaping of responsibility has been a push towards lifting scientific research principles above existing ethical constraints to achieve better results towards society. It is important not to abolish formal constraints and ethical review, as these are central in ensuring integrity in research, but rather evaluate how science can flourish within the legal and ethical framework towards societal benefit. [14].

Stilgoea and colleagues [11] suggest four dimensions of responsible innovation that comes out from the questions raised in public debates in the United Kingdom concerning new aspects of science and technology helping to characterise each dimension which helps explain the practicalities and provide standards and guidelines for meaningful directions in innovation management [11]. The first of the four is anticipation. The implications of new technologies and innovations are not always foreseeable, consequently anticipation encourages scientists and institutions to ask 'what if?' questions [15] to consider possibilities of the known, the likely and the plausible and what is indisputable. Anticipation implicates a structured approach directed to increase resilience, while unveiling further options for innovation and setting up the plans to study possible risks to the society [11]. The academic studies underline that requires comprehending the potential of future technologies for the anticipation to be successful [16]. The explanation of reflexivity as the second dimension suggests rethinking initial perceptions concerning people and values within science and innovation [17]. At an institutional level, reflexivity implies mirroring our actions, pledges, and expectations, understanding the framework of the known and the unknown and being respectful that any perceptions should be verified [11]. Scientific institutions have an obligation to contribute to strengthening reflexive capacity inside the organisation and to spread the general practise of science and innovation outside the organisation. This dimension encourages scientists to assume a broader moral responsibility of the possible implications and to act in an open and responsible manner within science and innovation [11]. The third dimension of responsible innovation suggested by Stilgoea is inclusion. The significance of public discussion [2] has become more evident in formulating questions that searched for hidden assumptions and commitments [18]. Although there has been some opposition to attempted efforts to introduce public discussions to avoid the risk of closure [2] or technocracy [19], attempts have been made to create a valuable system for the purpose of evaluating the meaningfulness of dialogue. In the last ten to twenty years, public platforms have been set up in a form of events or forums for deliberate interaction between members of stakeholders, scientists and wider public on the subject of science and innovation in the Northern Europe in particular [20]. The dimension of inclusion ultimately boils down to power. The institutions starting such initiatives have different means, approaches and targets when entering the dialogue. [2]. There should be time and space therefore for the public and stakeholders' to express their 
views both the policy issues and the deeper scientific perceptions [21] as well as the process of inclusion itself [22]. Responsiveness is the fourth dimension suggested for responsible innovation. There are a number of ways to allow for innovation to react to improvements in anticipation, reflexivity and inclusion [11]. This emphasises the fact society is as responsible for the implementation of innovation and the new technologies as are the innovators thus proving the systems of science and innovation to be coupled and diverse [11]. Responsible innovation implies the ability to implement changes in values or circumstances in response to interaction with public actors and stakeholders [2] thus scientific organisations cannot expect meaningful progress without being vigilant, responsive and fluid. We can look at scientific organisations as important actors having access to radical means to reconsider and reshape social, environmental and economic relations [23] and shifting to sustainability by introduction of transformative policies [8] the scale of the EU Green Deal. Interestingly, topdown policies in energy for example take decades to shift institutions and change the infrastructure, while a bottom-up grass root behavioural approach may cause rapid and widespread changes [24].

In fact, ethical acceptability and social attractiveness of the innovation process merely transforms science in a tool of diplomacy placing science, technology and innovation at the heart of achieving sustainability [25]. Although the application of a science diplomacy lens to a historical case that took place some 40 years before the concept's articulation [25], environmental diplomacy as a concept did not attain widespread scholarly purchase until the 1990s. International Environmental Diplomacy was published in 1988, consisting of contributions by political scientists, legal scholars, diplomats and government officials. The appearance of climate change as a global challenge is surprisingly recent. Toward the last decades of the $20^{\text {th }}$ century, much of the focus of science diplomacy moved beyond the role of science as a bridge to diplomatic dialogue and more toward the role of science interactions as the basis for addressing key global challenge [25]. The literature linking scientific advice, scientific bodies, and science diplomacy to climate change mitigation and adaptation is thin. [26]. While some cases use 'science for diplomacy' for further relations among countries, some cases aim for 'diplomacy for science' using foreign diplomacy or already established cooperation for the means of international scientific and technological collaboration [25]. Few scientific articles specifically link science diplomacy to climate change, for instance Hornsby and Parshotam [27] on how science diplomacy is exercised to strengthen scientific capability to attain food safety by sub-Sahara African States affected by climate change. The role of science diplomacy is investigated by Goodsite et al. [28] where the science diplomatic role of Arctic research stations was reviewed by answering how Arctic research stations connect scientists of Arctic and non-Arctic states.

However, science has been considered as a reasonable tool for communication and there we can give an example of Partnership of Research and Innovation in the Mediterranean Area (PRIMA) were the European Commission with the help of science diplomacy and ambitions policies has performed successfully in undertaking global challenges by attempting to put forward solutions for sustainable management of water resources and agrofood systems. The European Commission has also been active to maintain the dialogue between science and the policy makers in numerous academic conferences and events were a scientific approach to climate change has been provided.

Dogan [26] suggests three main objectives for science diplomacy:

1. Science in diplomacy, meaning to include a scientific dimension in reaching objectives in foreign policy. This is where science and technology play an advisory role to support policy objectives [29] COST or European Strategy Forum on Research Infrastructures here could be given as examples; 
2. Diplomacy for science, where international scientific cooperation is promoted. Its objective is to 'facilitate international cooperation, whether in pursuit of top-down strategic priorities for research or bottom-up collaboration between individual scientists and researchers' [30]. CERN is an example of this form of objectives.

3. Science for diplomacy, where international relations are stipulated by scientific cooperation as a tool. 'Science for diplomacy primarily draws on the 'soft power' of science' [28].

Scientific cooperation agreements, summer schools, science museums, online tours and different international educational dissemination activities are examples, facilitating worldwide relations between countries through the language of science. In climate change, science diplomacy has the potential of a more structured approach to learning through policy making by taking on an actor centric scheme to address the different agencies and interests [31]. Because particular climate change objectives require cumulative and jointly coordinated decisions over a lengthy course of time, well designed government initiatives of science diplomacy could reach excellent results [26]. The actual examples of science diplomacy with regard to global health, safety and the environment are built upon the significance of joining science and diplomacy efforts to respond more efficiently to global crises [32]. Returning to our discourse about the EU Green Deal policy in the context of the role of science in these movements, it is now the right moment for science to become a crucial part in climate change policy development and all the relevant actions [33].

Here we finish with theoretical explanation and continue with particular examples of what is behind both concepts 'responsible and innovative science' and 'science diplomacy' in one of the greatest laboratories of the world.

\section{Aвout CERN}

\subsection{What is CERN and How Complex is It?}

One of the largest research centres in the world CERN has been active from the middle of the last century. This international scientific institution established in 1954 to date has 23 member states and a web of over 40 states in varying roles in respect to CERN, mainly, associate member states, observer states, and non-member states with cooperation agreements. According to a commonly agreed upon notion among physicists, CERN was instrumental in establishing the European Physics Society. CERN was 'the cradle of society' in various facets: as a model, as an infrastructure, and as the initiator for the formation of a transnational network of individuals [32]. Within the scope of science diplomacy, CERN is regarded as having established an early precedent in institutionalised scientific cooperation [33], [34], having overcome historical and political disputes, thus providing a paramount depiction of the possibility of peace through science, by providing a common platform for individuals and countries alike [35], which illustrates the approach of mega or big science [36], and an important element of European integration [37]. The name 'CERN' is often regarded as a benchmark of the highest standards in execution and delivery in the world of scientific research. These standards, along with a one-of-a-kind approach, legal compliance and scientific organisational culture has attracted and retained the best and brightest minds in science and engineering. This has contributed to CERN's immersion and increase presence in worldwide discussions outside of its primary object of focus [38].

CERN's heightened attention towards both basic research and mega science [39] emphasizes the correlation and requirements for mediation between worlds of science and diplomacy [33]. After scrupulous research of existing literature and interviews with CERN 
and other international organisations, Höne and Kurbalija [33] argue that CERN offers an excellent example of how science and its practical applications can immediately contribute towards solving current worldwide obstacles while promoting a peaceful environment for establishing national and strategic concerns. This pattern inspired by CERN governance structure unifies science and diplomacy by uniquely building on a commonly agreed upon set of goals that outline the conduct of daily life. The success of this model can be regarded as a noteworthy framework for establishing governance bodies approaching science diplomacy in other institutions [33].

In this paper we suggest looking at this fantastic scientific organisation from two different angles. The first is from a technological perspective CERN has achieved enormous scientific results. Following the 2013 Nobel Prize in Physics being awarded to Peter Higgs and Francois Englert, CERN received an international prize for its contribution towards confirming the proposed Higgs-Boson particle. The Swedish Academy described CERN's Large Hadron Collider (LHC) as 'probably the largest and the most complex machine ever constructed by humans' [40]. The second angle from which to view the organisation is from the sociological perspective, the CERN community functions as an 'important connector among countries' [25] and actually embodies a combination of interactions between society, science, technology, economy and politics. This multidimensional complexity is furthered strengthened by considering the real-life limitations and requirements of CERN's Member States [38]. Both technological and societal aspects are interconnected behind through goals and values of the organisation.

\subsection{CERN Values through Communication}

As with every attempt to implement meaningful change, public support is instrumental and therefore communicating science to the public is of paramount importance if support is to be gained and maintained [41]. Conversely, absence or insufficiency of communication and responsiveness to public opinion can lead to mistrust and disbelieve in science. This establishes that the principles of transparency and openness are at the heart of any functional and successful relationship with the link between science and people being no exception. The transparency is a general principle encompassing clear motivation to drive chosen scientific pursuit, as well as making scientific research available to wider public [14].

In October 2017, the United Nations Office in Geneva held a public Open Day in which CERN was invited to participate. The Organization used the opportunity to show how research at CERN contributes to the UN's Sustainable Development Goals (SDGs) [42]. As it is explained in the CERN Annual report, there are five out of seventeen SDGs goals to which CERN contributes simply by carrying out its core mission. CERN promotes health and well-being through particle acceleration and detection technologies having a positive impact by wide spectrum of developments such as medical scanners and accelerators for hadron therapy. CERN's range of educational programmes such as summer schools and doctoral schools, exhibitions and open days serve students and teachers worldwide. The Laboratory promotes innovation through its knowledge transfer activities. The promotion of peaceful and inclusive societies is an integral part of CERN's governing convention. The final SDG goal aims to strengthen revitalising the global partnership for sustainable development. CERN is the epitome of international cooperation in the scientific world and continuously proves to be an example of effective practices in a multitude of scientific facets and other areas of human endeavour [42]. Among other highlights, CERN values clearly demonstrates an approach of open science - labelling itself as a pioneer in the field of open science, supporting opensource hardware (with the CERN Open Hardware Licence), open access (with the Sponsoring Consortium for Open Access Publishing in Particle Physics - SCOAP) and open data (with 
the CERN Open Data portal) [43]. The internationality of CERN might occasionally delay decision-making, however it is a small price to pay for having transparency and neutrality in the decision-making process.

This scientific organisation is highly concerned how to present the scientific achievements to the society. For CERN 'communication is both central and essential to the scientific process' [7]. CERN is very keen on educating students about leading-edge science, its values and complexity. In order to engage students, beyond its primary goal of education, CERN attempts to convey the excitement of having breath-taking discovery about universe and induces appreciation of the scientific method by experiencing it in leading-edge research [7], which has proven to be a well working approach of engagement through underground on site visits and virtual visits, both very popular and in high demand. CERN is a central institution that acts as a point of convergence and a bar of standards in the world of fundamental physics [38]. We could regard an organisation's centrality by the measure of working relationships and interactions between the representatives of the organisation of origin and the other representatives in the respective field, as well as the number of instances people either attend meetings or read publications hosted and provided by the organisation. The 2019 user community statistics verifies CERN's broad reach. In addition to staff members, CERN employed 770 fellows, trained 520 students and hosted 1285 associates. CERN's infrastructure and services were used by a large scientific community of 12427 users from over 70 countries [43].

Among other scientific objectives CERN emphasises the importance of setting environmental goals for the future and communicates this through various channels. Having established the notions of shifting environmental understanding in the EU, CERN has enriched its field of focus with environmental challenges similarly outlined in EU's Green Deal.

For CERN 'communication is both central and essential to the scientific process' [6]. CERN is very keen on educating students about leading-edge science, its values and complexity. Efforts are made not only to educate the students, but also to convey the excitement of discovery and to foster a deeper appreciation of the scientific method by witnessing its application first hand in leading-edge research [6], which has proven to be a well working approach to engagement as underground visits, virtual visits are very popular and heavily demanded. CERN is an anchor institution that acts as a well-established fundamental physics hub that people look to and converge around.

\subsection{CERN and Environment}

There are several directions for CERN to be engaged in environmental discourse. The European Strategy for Particle Physics unquestionably being the edge of Europe's policy planning for the longstanding future of the field. Suggestions for the recent updates was transferred through several working groups including group of Sustainability and Environmental impact. The suggestions are following.

1. HEP experimental activities, with respect to the emission of greenhouse and other gases should be supported and expanded. All new projects should present an environmental impact assessment and a plan to minimise such impact as part of the project approval process.

2. The energy efficiency of existing and potential accelerators, and of IT facilities, should remain an area needing continuous supervision. A comprehensive strategy for energy saving and the energy consumption reduction should be an integral part of the proposal for any future accelerator project.

3. CERN and HEP must play a role in developing new technologies that can positively 
affect (reduce) energy consumption, e.g. in the areas of HTSC or energy recovery. Such efforts should be strengthened.

4. To reduce travels into alternatives such as virtual or better video meetings.

Another great example - The Paul Scherrer Institute, in collaboration with CERN (The European Organization for Nuclear Research), ERF (The European Association of National Research Facilities), ESS (The European Spallation Source) are organising workshops in the series 'Energy for Sustainable Science at Research Infrastructures' that brings together all stakeholders from all over the world and as invitation says 'to identify the challenges, best practices and policies to develop and implement sustainable solutions at research infrastructures. This includes the increase of energy efficiencies, energy system optimizations, storage and savings, implementation and management issues as well as the review of challenges represented by potential future technological solutions and the tools for effective collaboration'.

Apart from the communication and dissemination activities to strengthen environmentally responsible approach in the organisation, CERN Environmental Protection Steering board is established in 2016. First recommendations come out in 2017, and in 2018 they were put in practice. As current Director-General Dr. Fabiola Gianotti underlines in her introductory message of CERN annual report 'During 2019 the CERN Environmental Protection Steering board oversaw excellent progress in the implementation of its recommendations for highpriority measures to minimise CERN's impact on the environment.' While all advanced technology is underground, some infrastructure elements on the surface are as old as CERN itself and have to be refurbished. As an example of the great progress - beamlines are being renewed, and power converters dating from the 1950s are being replaced. New power converters for the East area mean electricity consumption is expected to fall from $11 \mathrm{GWh} /$ year to $0.6 \mathrm{GWh} /$ year [43]. Data collected on analysis of information about environmental activities in CERN annual reports shows environmental activities before 2016 are mostly focused on monitoring, safety and protection measures helping to avoid the risk of water pollution, radiation and electrical hazards. Whereas those suggesting the implementation of advanced heating - cooling, energy efficiency technologies, sewer system optimisation, heat recovery systems and waste treatment technologies are introduced in the later years.

Besides existing infrastructure ambitious programme about Future Circular Collider (FCC) has been started. The FCC programme has strong commitments towards sustainable development and an environmentally friendly research infrastructure. First projects clearly confirm awareness of FCC collaboration regarding the ecological and economic consequences of energy usage and believes that sound energy management is critical. Some of directions are considered: development of power efficient equipment and infrastructure, innovative solutions for cooling, recycling from construction sites concerning the philosophy of a circular economy, generate energy from waste for other purposes and provide energy awareness trainings for end-users. 


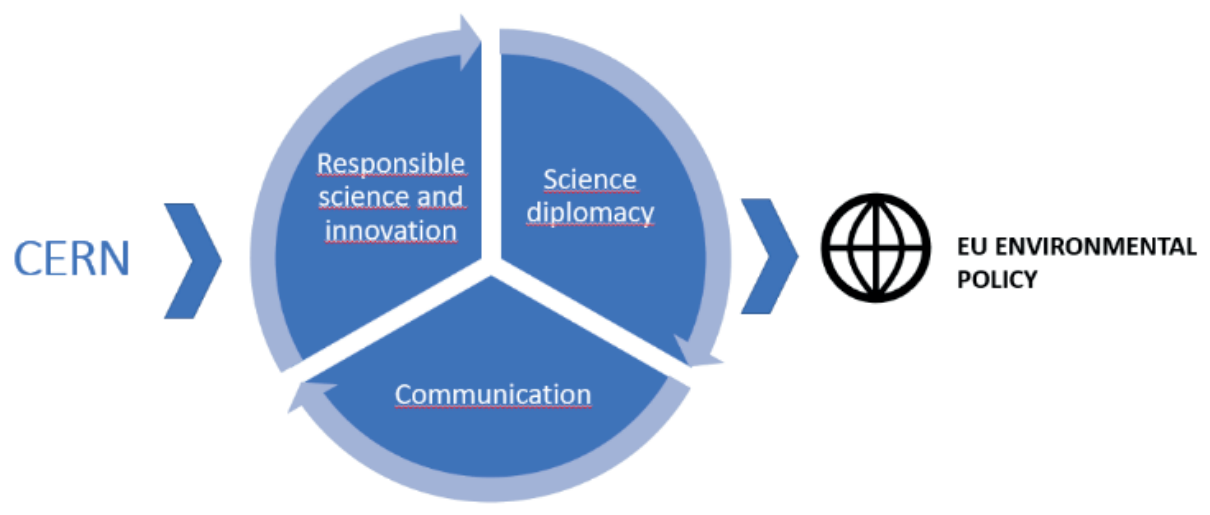

Fig. 1. Mechanism of science diplomacy and responsible science addressing global challenges.

CERN moves firmly towards being a responsible actor in environmentally responsible research and environmental targets in its first environmental report issued in the beginning of 2020. The report includes clearly set energy savings targets for reduced energy consumption, reduced emissions, decrease in noise pollution, more recycled waste, as well as knowledge transfer of developed innovative green solutions. 'Today, more than ever, science's flagbearers need to demonstrate their relevance, their engagement, and their integration into society as a whole'. In the foreword of the environmental report CERN Director-General Dr. Fabiola Gianotti admits 'It is our vision for CERN to be a role model for environmentally responsible research' [44].

\subsection{Is it Safe to Live near CERN?}

The authorities' responsibility was traditionally limited to the 'products' of science and innovation, in particular impacts later to be found harmful to health or the environment or otherwise unacceptable [11]. Mirroring this notion there has always been something unknown and mysterious about CERN. 'What is it like to live near the CERN super collider? Are there special safety drills and precautions?' - such questions are raised in one of the worldwide questions and answers communities Quora. A provocative question 'Will the Large Hadron Collider Destroy Earth?' sits as a title on the LivesScience webpage.

The lack of visual confirmation is amongst one of many factors surrounding the uncertainty - LHC is entirely underground and not visible to the public. What we do not see, does not exist or is surrounded by mystery. Only in 2010 the Geneva city train system was extended all the way to Meyrin, where CERN is located and thus became easy accessible to locals and guests. The real estate market surrounding CERN has developed only in the last years, proving CERN efforts to clarify the absence of eminent danger to have been successful. Although CERN has maintained very strong environmental protection and safety procedures required be legislation of France and Switzerland incorporated in organisational strategies, apparently it is useful to periodically communicate with the local communities about organisation values and priorities. Besides, for the transformations in new technologies need to be linked with sound educational principles, new accounts in social, environmental and economic interrelations, and alterations in perception [9]. 


\section{CONCLUSION}

In this article we looked at the intersections of two concepts in order to contribute to broader discussions in both research and governance communities, to establish how researchers should conduct their science, and what respective responsibilities researchers and their institutes have towards the European Green Deal policy.

According to the politics of the Green Deal announced in late 2019, research and innovation are the main booster of the environmental, social and economic changes introduced by the Green Deal programme to tackle climate change. While the innovative environment actions, although important, might not be top priority of every scientific organisation, science and technology are not just technical but also influence the social and policy sector and thus the values represented by science and technology provide a good precedent for others. Nevertheless, responsible innovation necessitates fluidity and responsive action to influence public opinion, social and ethical values. Nevertheless, for integration of the worthwhile idea of expected changes in policy and science, we have to be particular in societal issues to be reached, with clear strategy and timeline [30]. In the article we also had a look at responsible innovation through the lens of four dimensions of responsible innovation - anticipation, reflexivity, inclusion and responsiveness suggested by Stilgoea and colleagues. These four dimensions are useful attributes towards responsible innovation and are beneficial tools for policy makers [11].

However, there is a continuous need to explore theoretical discourse through actual cases. The case study is currently based on preliminary literature and media research regarding one of the world's largest research centres CERN. Among other scientific objectives, CERN emphasises the importance of setting environmental goals for the future and communicates this through various channels. In its Annual report of 2017, the organisation describes itself as 'a model for global cooperation in science' by inspiring and promising guidance in various aspects of science and further areas of human endeavour. Subsequently the first Environmental report of the organisation was published in the beginning of 2020 with clear statements relevant to the European Green Deal. Infrastructure reconstruction works towards energy savings were also started recently.

Looking at the examples included in this paper, our intention was to demonstrate the approach and methods of one of the greatest scientific organisations to be part of a successful global transformation of responsible science through a wide range of activities including science diplomacy and communication, particularly in the context of climate change mitigation and adaptation.

However, to establish the wide spectrum of opportunities in modelling sustainable development and what practical steps should be made to balance capabilities and capacity of the science community with the goals set out within the Green Deal, further investigations, models and analysis should be conducted. Moreover, there is lot of room for a science, policy and action-oriented discussion of climate-related policy issues that bridge disciplines, sectors and themes. There is also a need to understand the expectations of society, EU environmental policy makers and other stakeholders. Are their expectations for innovation and responsible science similar to scientists and innovators? What is the idea of others on how science can participate in the movement towards a safer and greener planet? The tangible discussion begins when answers to the abovementioned questions are received from a wider audience. Only then can we start to formulate what responsible science means in the context of research and innovation in the European Green Deal and what types of action are likely helpful to policymakers and research organisations to fully achieve responsible innovation. 


\section{ACKNOWLEDGEMENT}

The research was supported by the Shota Rustaveli National Science Foundation of Georgia [Grant No. CARYS-192345].

\section{REFERENCES}

[1] Nikas A., et al. Perspective of comprehensive and comprehensible multi-model energy and climate science in Europe. Energy 2021:215:119153. https://doi.org/10.1016/j.energy.2020.119153

[2] Stirling A. Opening up and closing down: power, participation, and pluralism in the social appraisal of technology. Science Technology \& Human Values 2008:33:262-294. https://doi.org/10.1177/0162243907311265

[3] Davies D., et al. Creative learning environments in education-A systematic literature review. Thinking Skills and Creativity 2012:8:80-91. https://doi.org/10.1016/j.tsc.2012.07.004

[4] Gough D., Oliver S., Thomas J. An introduction to systematic reviews (2 $2^{\text {nd }}$ ed.). London: Sage, 2017.

[5] Bhattacherjee A. Social science research: Principles, methods, and practices. Textbooks collection 3 ( ${ }^{\text {nd }}$ ed.). Tampa: University of South Florida, 2012.

[6] Sharif B. The relations between acculturation and creativity and innovation in higher education: A systematic literature review. Educational Research Review 2019:28:100287. https://doi.org/10.1016/j.edurev.2019.100287

[7] Goldfarb S., Marcellonib C., Shaw K. Innovating science communication: the structure supporting ATLAS Education \& Outreach. Nuclear and Particle Physics Proceedings 2016:273-275:1276-1283. https://doi.org/10.1016/j.nuclphysbps.2015.09.204

[8] Bloomfield J., Steward F. The Politics of the Green New Deal. The Political Quarterly 2020:91(4):770-779. https://doi.org/10.1111/1467-923X.12917

[9] Linnér B. O., Wibeck V. Conceptualising variations in societal transformations towards sustainability. Environmental Science and Policy 2020:106:221-227. https://doi.org/10.1016/j.envsci.2020.01.007

[10] Skjærseth J. B. Towards a European Green Deal: The evolution of EU climate and energy policy mixes. International Environmental Agreements 2021:21:25-41. https://doi.org/10.1007/s10784-021-09529-4

[11] Stilgoea J., Owen R., Macnaghten P. Developing a framework for responsible innovation. Research Policy 2013:42(9):1568-1580. https://doi.org/10.1016/j.respol.2013.05.008

[12] Landeweerd L., et al. Reflections on different governance styles in regulating science: a contribution to 'Responsible Research and Innovation'. Life Sciences, Society and Policy 2015:11. https://doi.org/10.1186/s40504-015-0026-y

[13] Owen R., et al. A Framework for Responsible Innovation. Responsible Innovation: Managing the Responsible Emergence of Science and Innovation in Society. Chichester: Wiley, 2013:27-50.

[14] Lacey J., Coates R., Herington M. Open science for responsible innovation in Australia: understanding the expectations and priorities of scientists and researchers. Journal of Responsible Innovation 2020:7(3):427-449.

[15] Ravetz J. The science of 'what-if?' Futures 1997:29:533-539. https://doi.org/10.1080/23299460.2020.1800969

[16] Borup M., et al. The sociology of expectations in science and technology. Technology Analysis \& Strategic Management 2006:18:285-298. https://doi.org/10.1080/09537320600777002

[17] Swierstra T., Rip A. Nano-ethics as NEST-ethics: patterns of moral argumentation about new and emerging science and technology. NanoEthics 2007:3:3-20. https://doi.org/10.1007/s11569-007-0005-8

[18] Lövbrand E., Pielke R., Beck S. A democracy paradox in studies of science and technology. Science, Technology \& Human Values 2011:36:474-496. https://doi.org/10.1177/0162243910366154

[19] Rose N. Powers of Freedom: Reframing Political Thought. Cambridge: Cambridge University Press, 1999.

[20] Wilsdon J., Willis R. See-Through Science. Demos, London: Demos, 2004.

[21] Jasanoff S. Technologies of humility: citizen participation in governing science. Minerva 2003:41:223-244. https://doi.org/10.1023/A:1025557512320

[22] van Oudheusden M. Questioning 'participation': a critical appraisal of its conceptualization in a Flemish participatory technology assessment. Science and Engineering Ethics 2011:17:673-690. https://doi.org/10.1007/s11948-011-9313$\underline{z}$

[23] Gillard R., et al. Transformational responses to climate change: beyond a systems perspective of social change in mitigation and adaptation. WIREs Clim. Change 2016:7:251-265. https://doi.org/10.1002/wcc.384

[24] Pacala S., Socolow R. Stabilization wedges: solving the climate problem for the next 50 years with current technologies. Planning for Climate Change: A Reader in Green Infrastructure and Sustainable Design for Resilient Cities. Oxfordshire: Tayler and Francis, 2018:55-61.

[25] Turekian V. The Evolution of Science Diplomacy. Global Policy 2018:9(3):5-7. https://doi.org/10.1111/17585899.12622

[26] Özkaragöz D. E., Uygun Z, Akçomak I. S. Can science diplomacy address the global climate change challenge? Environmental Policy and Government 2021:31:31-45. https://doi.org/10.1002/eet.1911 
[27] Hornsby D. J., Parshotam A. Science diplomacy, epistemic communities, and practice in sub-Saharan Africa. Global Policy 2018:9(3):29-34. https://doi.org/10.1111/1758-5899.12565

[28] Goodsite M. E., et al. The role of science diplomacy: A historical development and international legal framework of arctic research stations under conditions of climate change, post-cold war geopolitics and globalization/power transition. Journal of Environmental Studies and Sciences 2016:6(4):645-661. https://doi.org/10.1007/s13412-0150329-6

[29] Davis L. S., Patman, R. G. New day or false Dawn? Science diplomacy - New day or false Dawn? Singapore: World Scientific Publishing, 2015:261-275.

[30] The Royal Society. New frontiers in science diplomacy: Navigating the changing balance of power. London: The Royal Society, 2010.

[31] Copeland D. Science Diplomacy. The Sage Handbook of Diplomacy. Thousand Oaks: Sage, 2016:628-641.

[32] Hölscher J. K., Wittmayer J. M., Loorbach D. Transition versus transformation: What's the difference? Environ. Innovation Societal Transitions 2018:27:1-3. https://doi.org/10.1016/j.eist.2017.10.007

[33] Hone K. E., Kurbalija J. Accelerating Basic Science in an Intergovernmental Framework: Learning from CERN's Science Diplomacy. Global Policy 2018:9(3):67-72. https://doi.org/10.1111/1758-5899.12589

[34] Lalli R. (2021) Crafting Europe from CERN to Dubna: Physics as diplomacy in the foundation of the European Physical Society. Centaurus 2021:63:103-131. https://doi.org/10.1111/1600-0498.12304

[35] Quevedo F. Science and Diplomacy. The Importance of International Research Institutions for Science Diplomacy. 2013 [Online]. [Accessed dd.mm.yyyy]. Available: https://www.sciencediplomacy.org/perspective/2013/importanceinternational-research-institutions-for-science-diplomacy

[36] Ruffini P.-B. Science and Diplomacy. A New Dimension of International Relations. New York: Springer, 2017.

[37] Stein J. A. Science, Technology and European Foreign Policy: European Integration, Global Interaction. Science and Public Policy 2002:29(6):463-477. https://doi.org/10.3152/147154302781780787

[38] Robinson M. The CERN Community; A Mechanism for Effective Global Collaboration? Global Policy 2019:10(1). https://doi.org/10.1111/1758-5899.12608

[39] Lami S. Science \& Diplomacy. Challenges and New Requirements for International Collaborations. 2017 [Online]. [Accessed 15.04.2021]. Available: https://www.sciencediplomacy.org/article/2017/mega-science-collaborations

[40] Royal Swedish Academy of Sciences (2013) The Nobel Prize in Physics 2013

[41] Palmer S. E., Schibeci R. A. What Conceptions of Science Communication are Espoused by Science Research Funding Bodies? Public Understanding of Science 2014:23:511-527. https://doi.org/10.1177/0963662512455295

[42] CERN. CERN Annual Report 2017. Geneva: CERN, 2018.

[43] CERN. CERN Annual Report 2019. Geneva: CERN, 2019.

[44] CERN. CERN Environmental Report 2017-2018. Geneva: CERN, 2019. 